Supplement of Geosci. Model Dev., 9, 3137-3160, 2016

http://www.geosci-model-dev.net/9/3137/2016/

doi:10.5194/gmd-9-3137-2016-supplement

(c) Author(s) 2016. CC Attribution 3.0 License.

(c) (i)

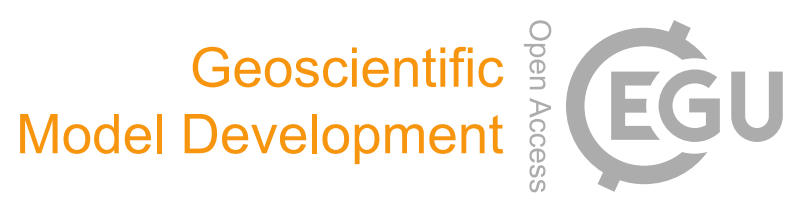

Supplement of

\title{
Evaluation of the boundary layer dynamics of the TM5 model over Europe
}

\section{E. N. Koffi et al.}

Correspondence to: E. N. Koffi (ernest.koffi@jrc.ec.europa.eu)

The copyright of individual parts of the supplement might differ from the CC-BY 3.0 licence. 


\section{Comparison of IGRA boundary layer heights to ceilometer observations at Cabauw}
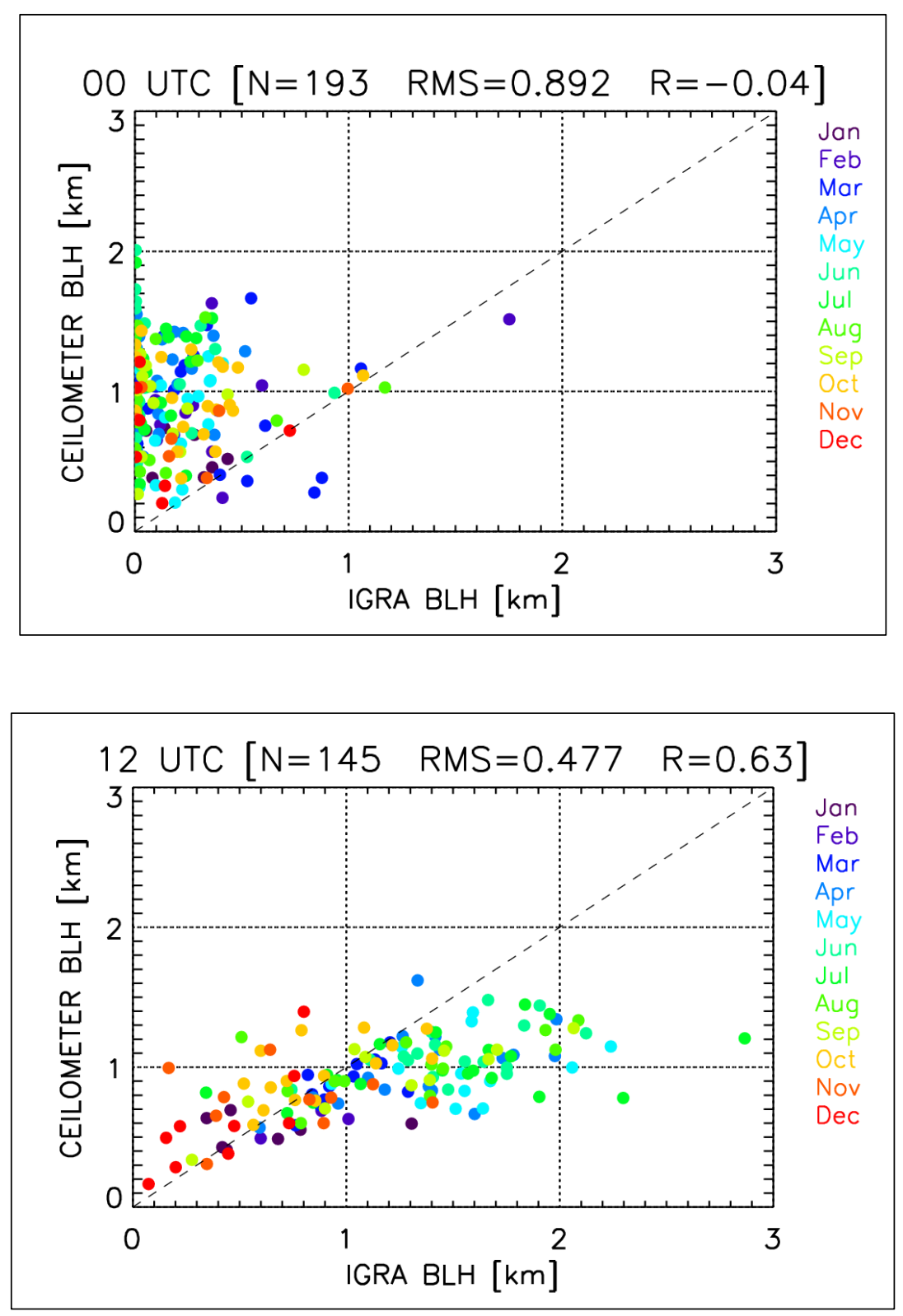

Figure S1: The Cabauw ceilometer boundary layer heights versus IGRA (De Bilt station) data for the year 2010 at 00 (on the top) and 12 (bottom) UTC are shown. The statistics (RMS in km and correlation coefficient R) are indicated as well as the number of pair of data (N) used to compute these metrics. The different colors indicate the months at which the data were obtained. 


\section{Comparison of TM5 boundary layer heights to observations}

We extract the BLH in the model both at the location of the InGOS station and at the location of the nearest IGRA station, resulting in a set of four different modeled BLHs labelled by the following acronyms:

- 'TM5': TM5 default version (Eq.1 in Section 2.1 with $\mathrm{R}_{\mathrm{ic}}=0.3$ ); extracted at InGOS stations by using 2D interpolation

- 'TM5_IGRA': As 'TM5', but extracted at IGRA station, which is closest to the selected InGOS station

- 'TM5_INGOS': BLHs computed in TM5 model adopting the InGOS definition of the BLH (i.e., $\mathrm{R}_{\mathrm{ic}}=0.25$ and both surface wind and stress velocity are set to zero in Eq.1), extracted at InGOS station. The BLH of the closest model grid point to the selected station is considered.

- 'TM5_INGOS_IGRA': As 'TM5_INGOS', but extracted at IGRA station, which is closest to the selected InGOS station

Furthermore, we evaluate the BLHs as provided by ECMWF analyses and interpolated to TM5 grids (labelled 'ECMWF'). The values of these BLHs are extracted only at the InGOS stations.

For other details see Section 3.2 of the text of the main paper

We show in the following the time series for year 2009. 


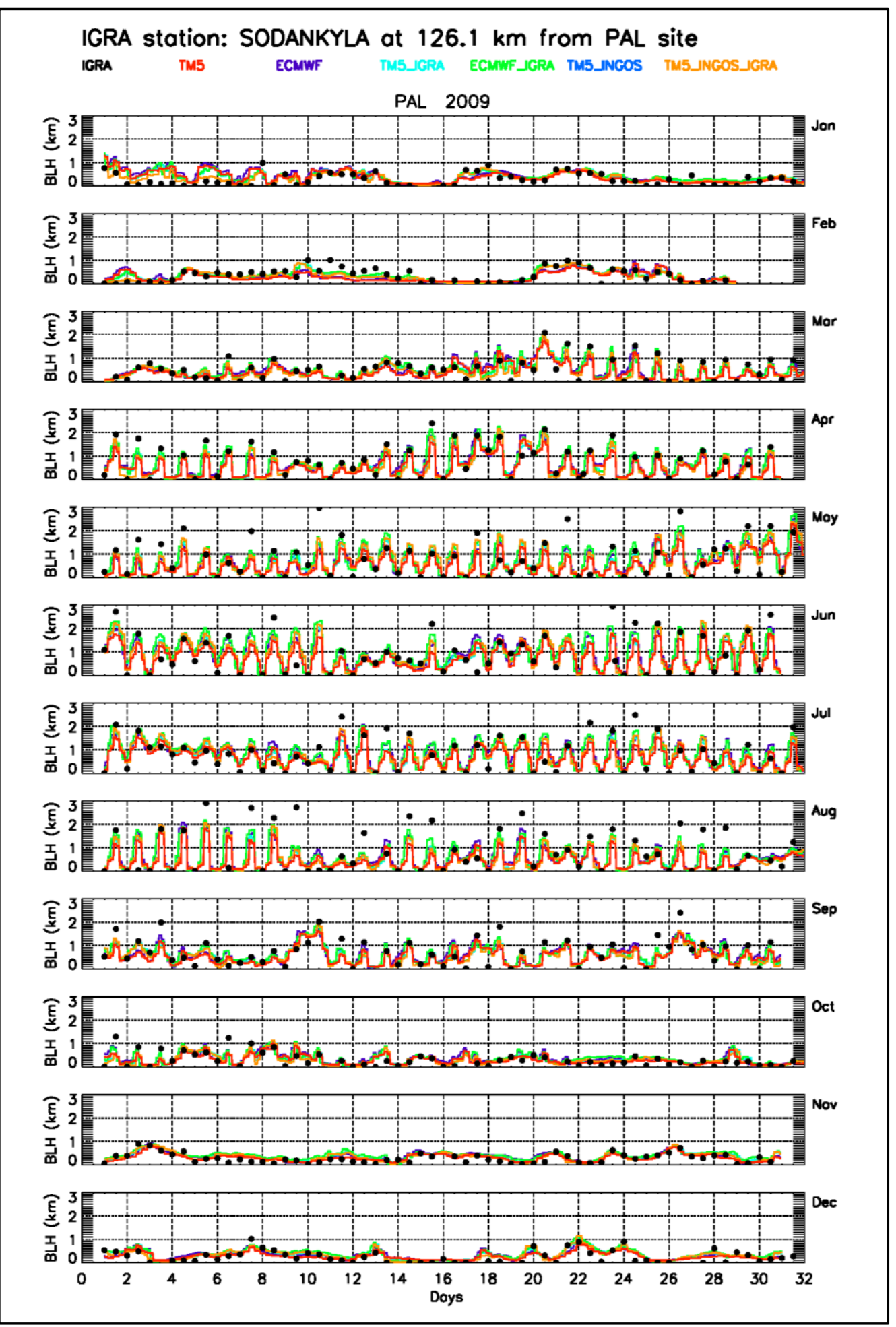

Figure S2: Time series of observed (IGRA in black dot) and modelled (TM5, TM5_IGRA, TM5_INGOS, and TM5_INGOS_IGRA in colors) boundary layer heights for InGOS station Pallas (PAL). The closest IGRA station to Pallas is Sodankyla. The distance between IGRA and InGOS stations is given of the top of graph. The different model acronyms are defined at page 3 in this document 


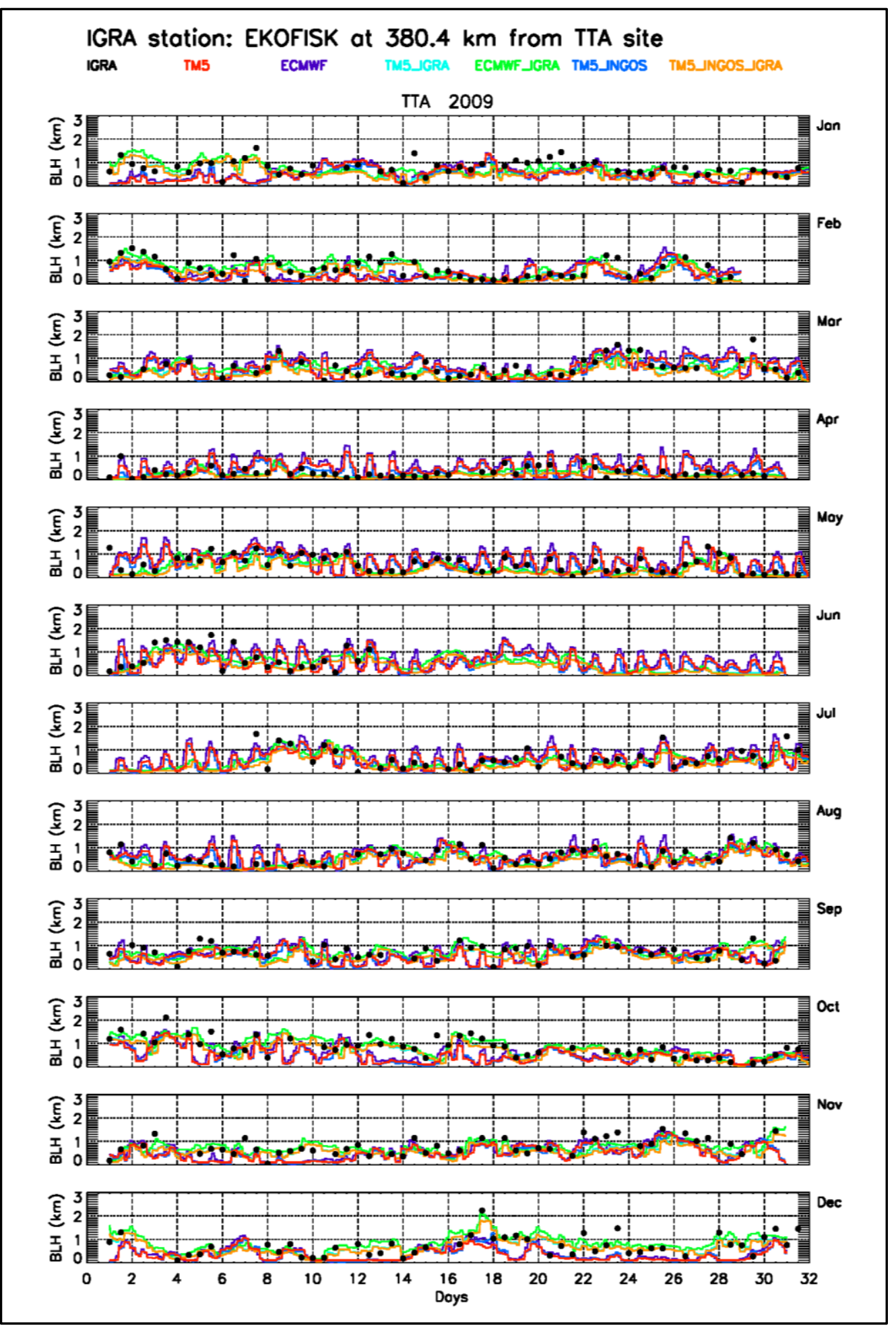

Figure S3: As Figure S2, but for the InGOS station Angus (TTA) 


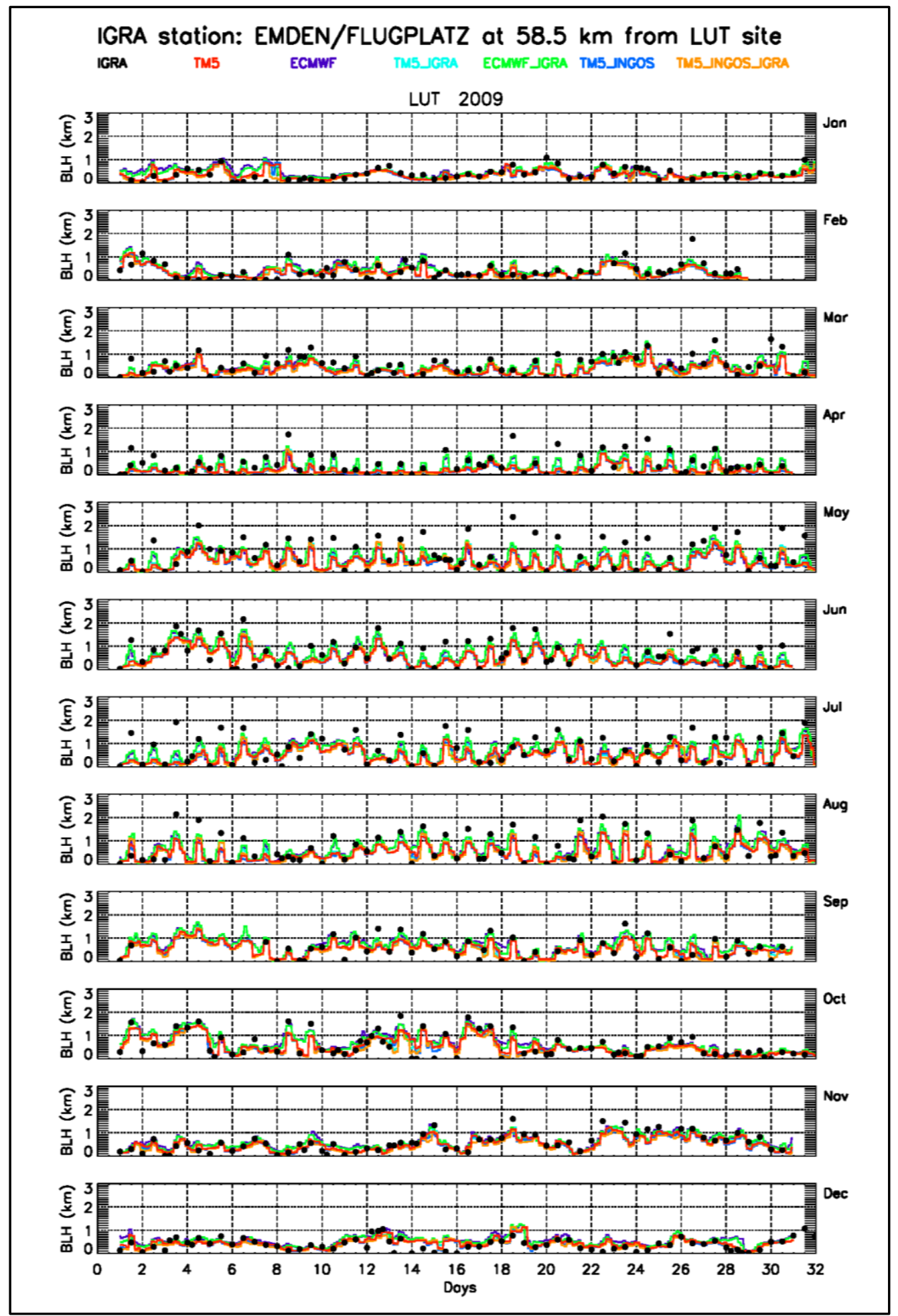

Figure S4: As Figure S2, but of the InGOS station Lutjewad (LUT) 


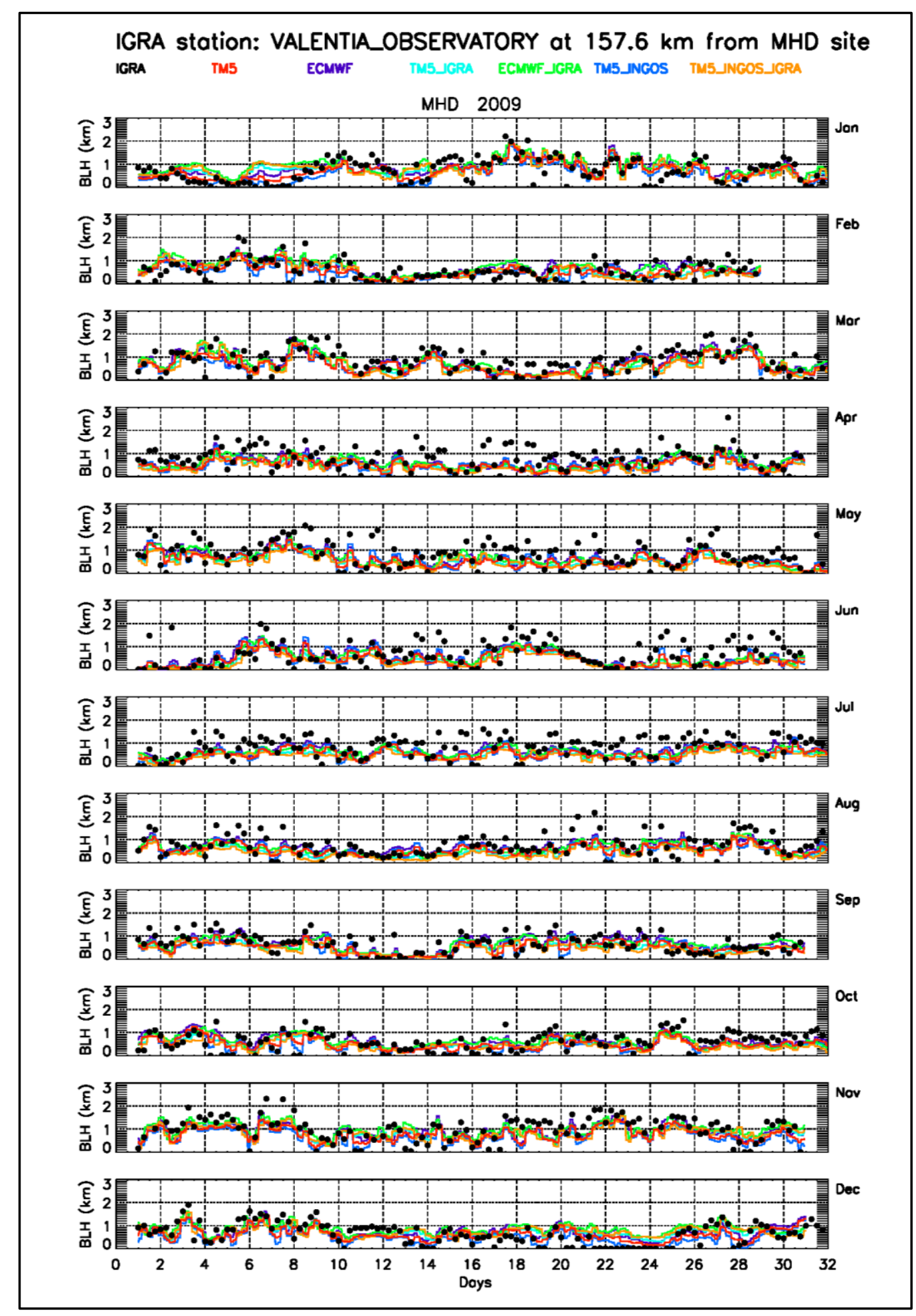

Figure S5: As Figure S2, but for the InGOS station Mace Head (MHD) 


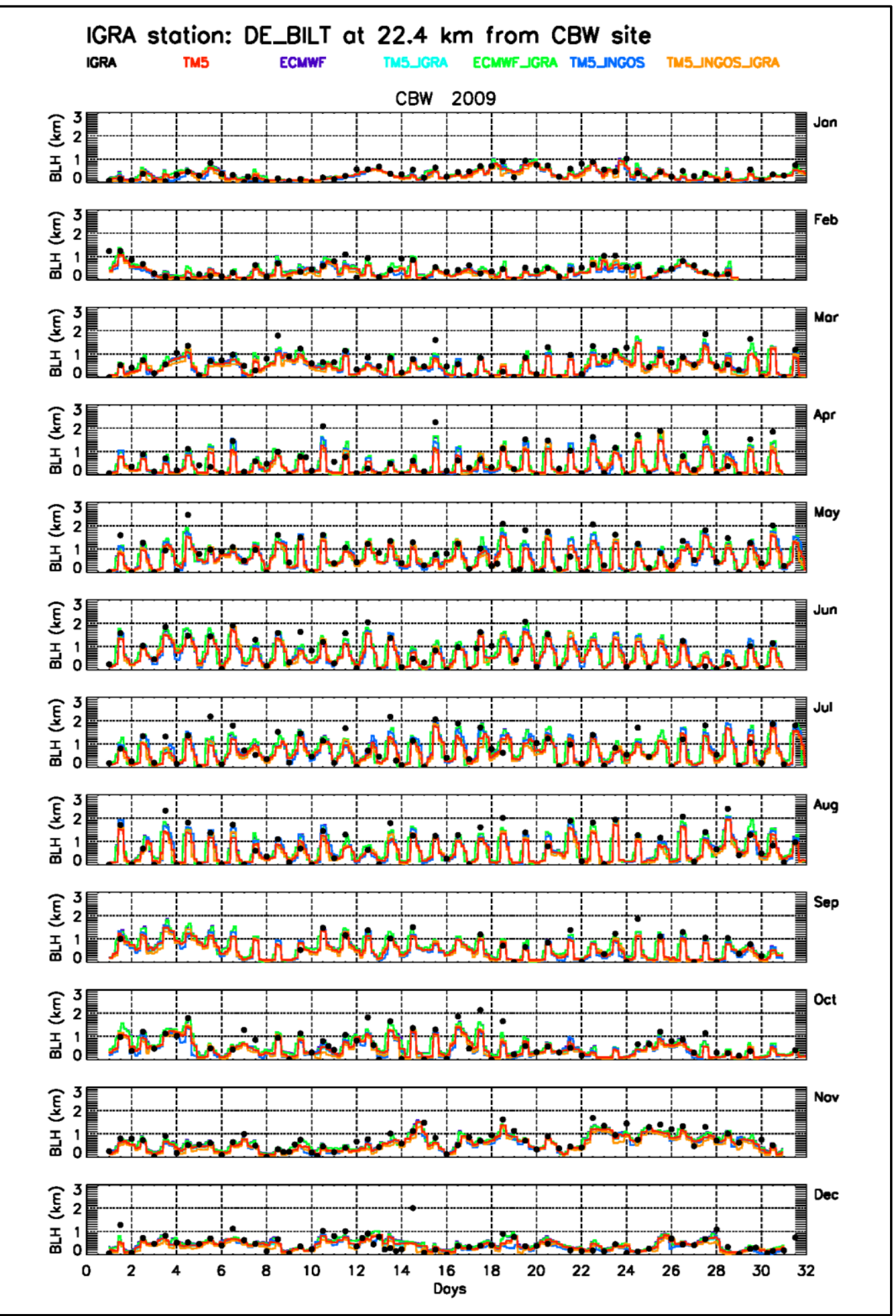

Figure S6: As Figure S2, but for the InGOS station Cabauw (CBW or CB1/CB4) 


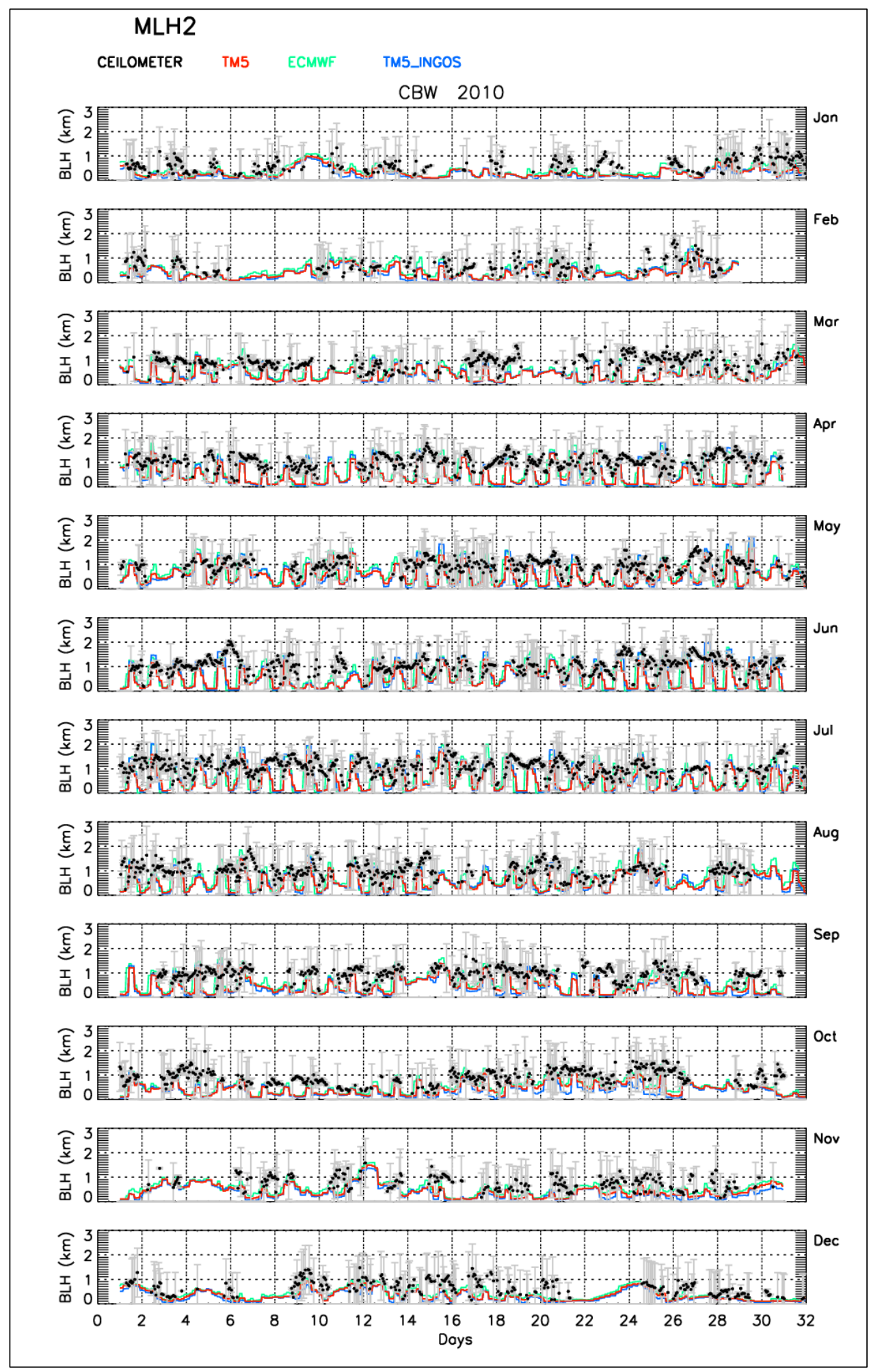

Figure S6b: As for Figure S6, but the observations for the year 2010 are from the ceilometer measurements at Cabauw (CBW). The standard deviations over $1 \mathrm{~h}$ period are shown in grey 


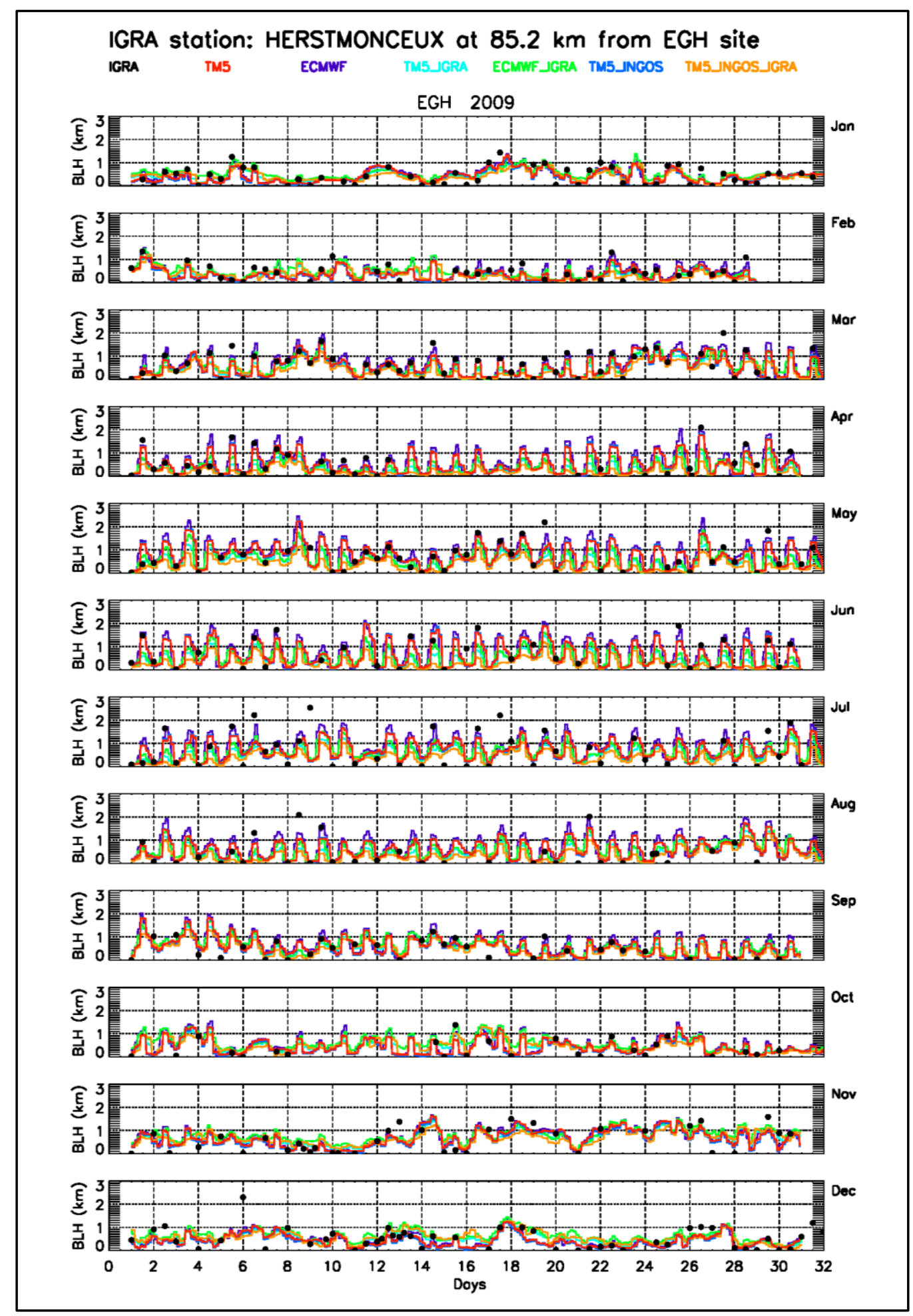

Figure S7: As Figure S2, but for InGOS station Egham (EGH) 


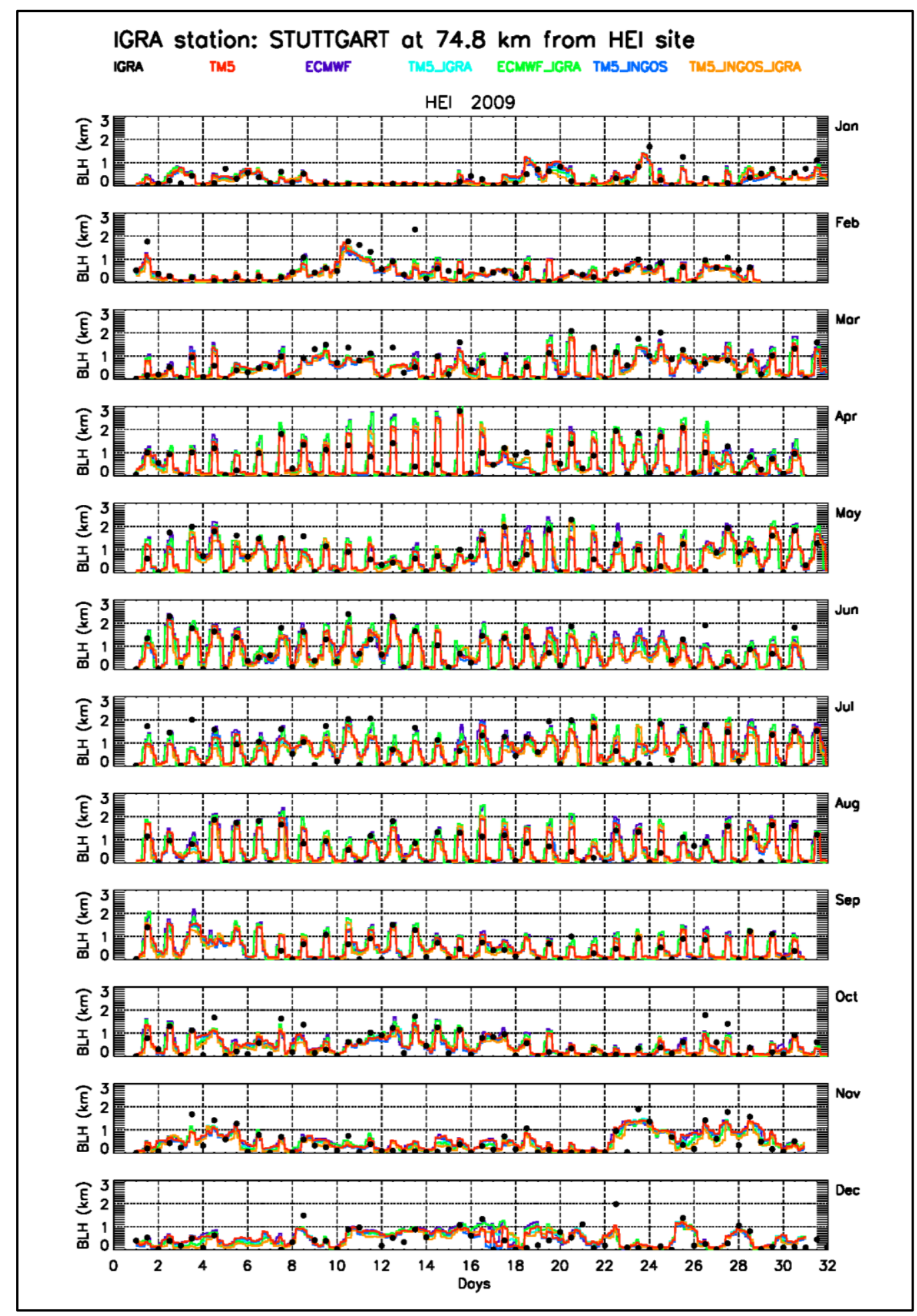

Figure S8: As Figure S2, but for InGOS station Heidelberg (HEI) 


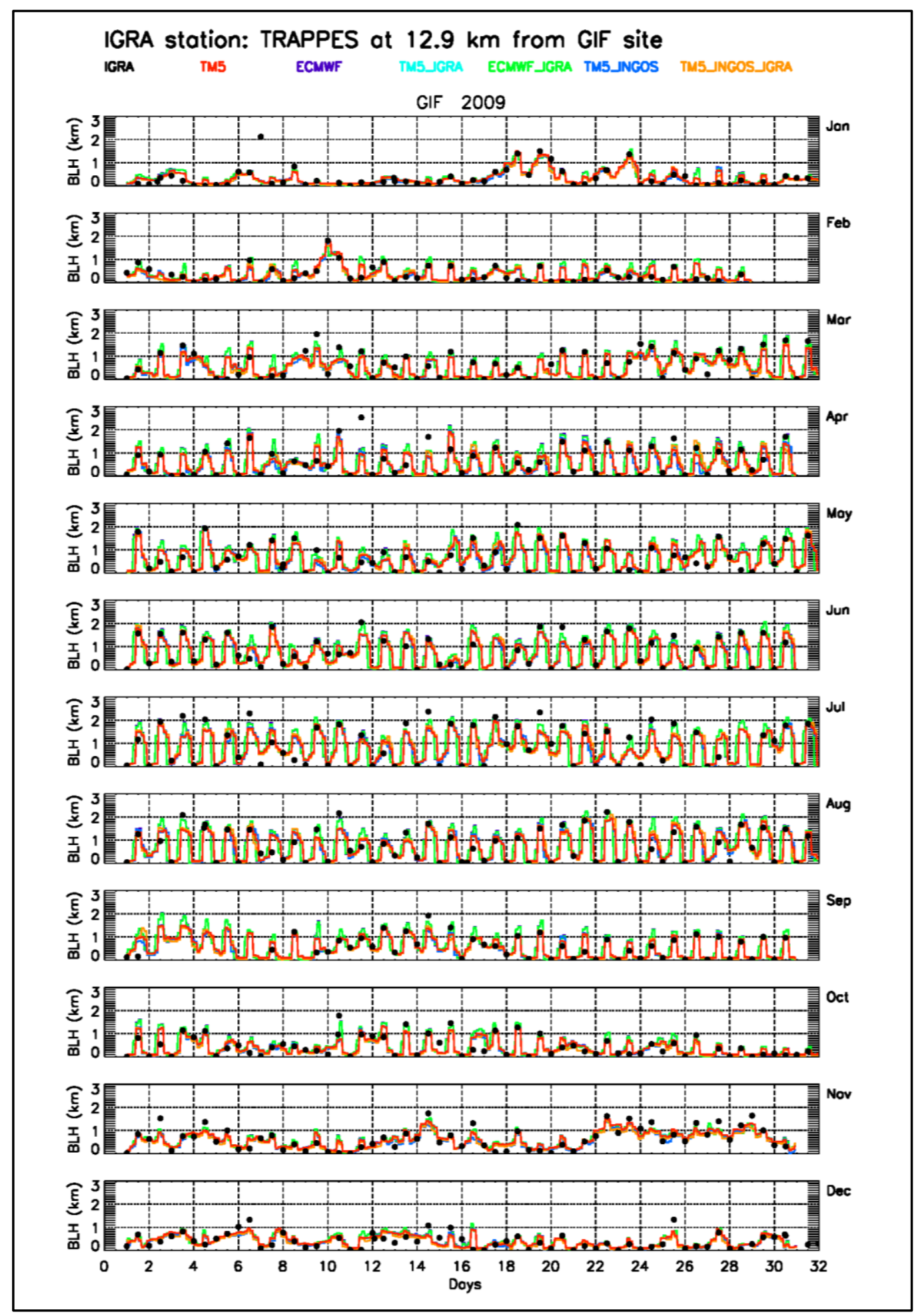

Figure S9: As Figure S2, but for InGOS station Gif sur Yvette (GIF) 


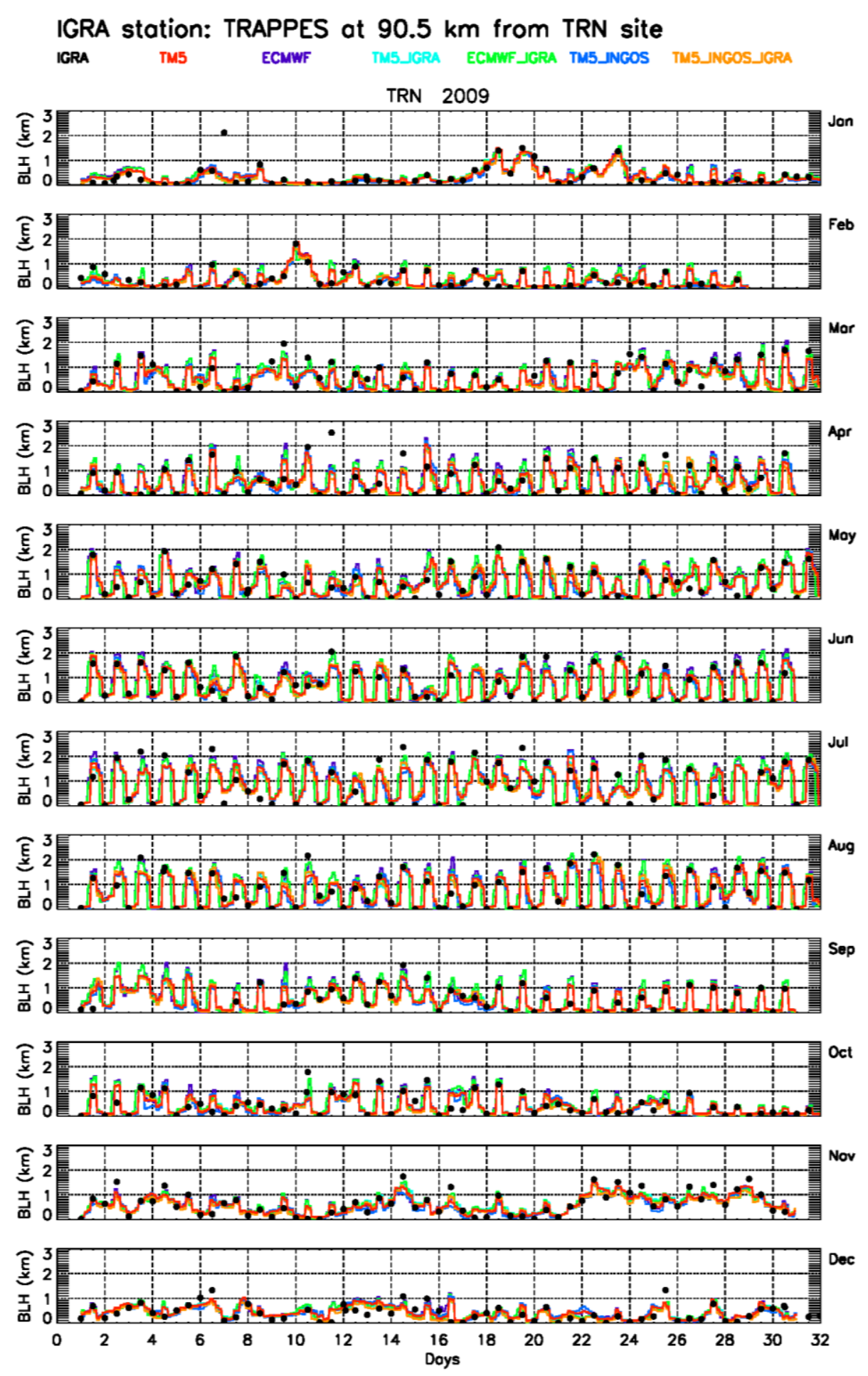

Figure S10: As Figure S2, but for the InGOS station Trainou (TRN or TR4) 


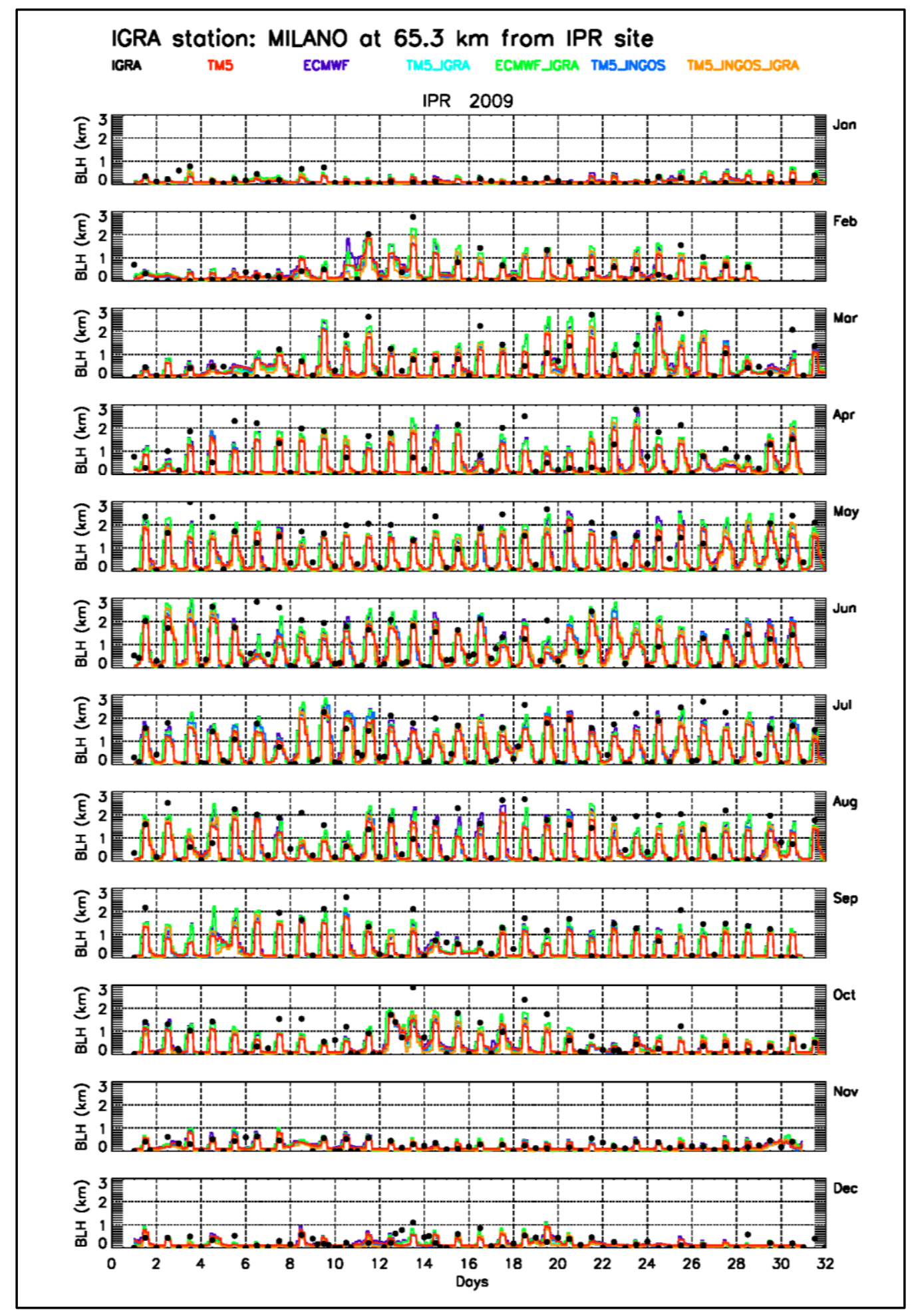

Figure S11: As Figure S2, but for the InGOS station Ispra (IPR) 


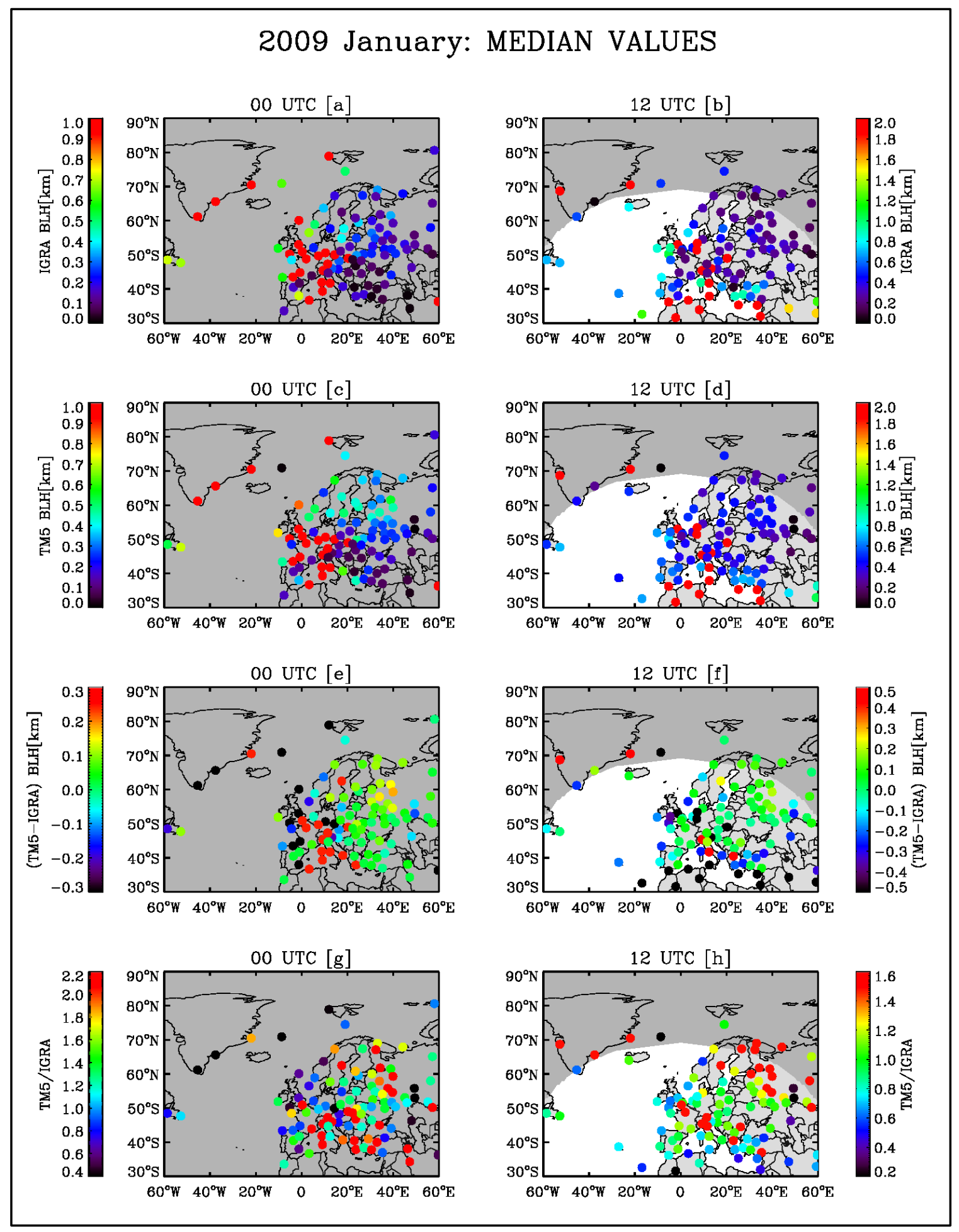

Figure S12: Median values of IGRA and TM5 boundary layer heights [a, b, c, and d] together with their differences (TM5-IGRA) [e and f] for January 2009 are shown. The median values of the ratios between TM5 and IGRA boundary layer heights (TM5/IGRA) [g and h] are also displayed. Left: 00UTC; right: 12 UTC. 


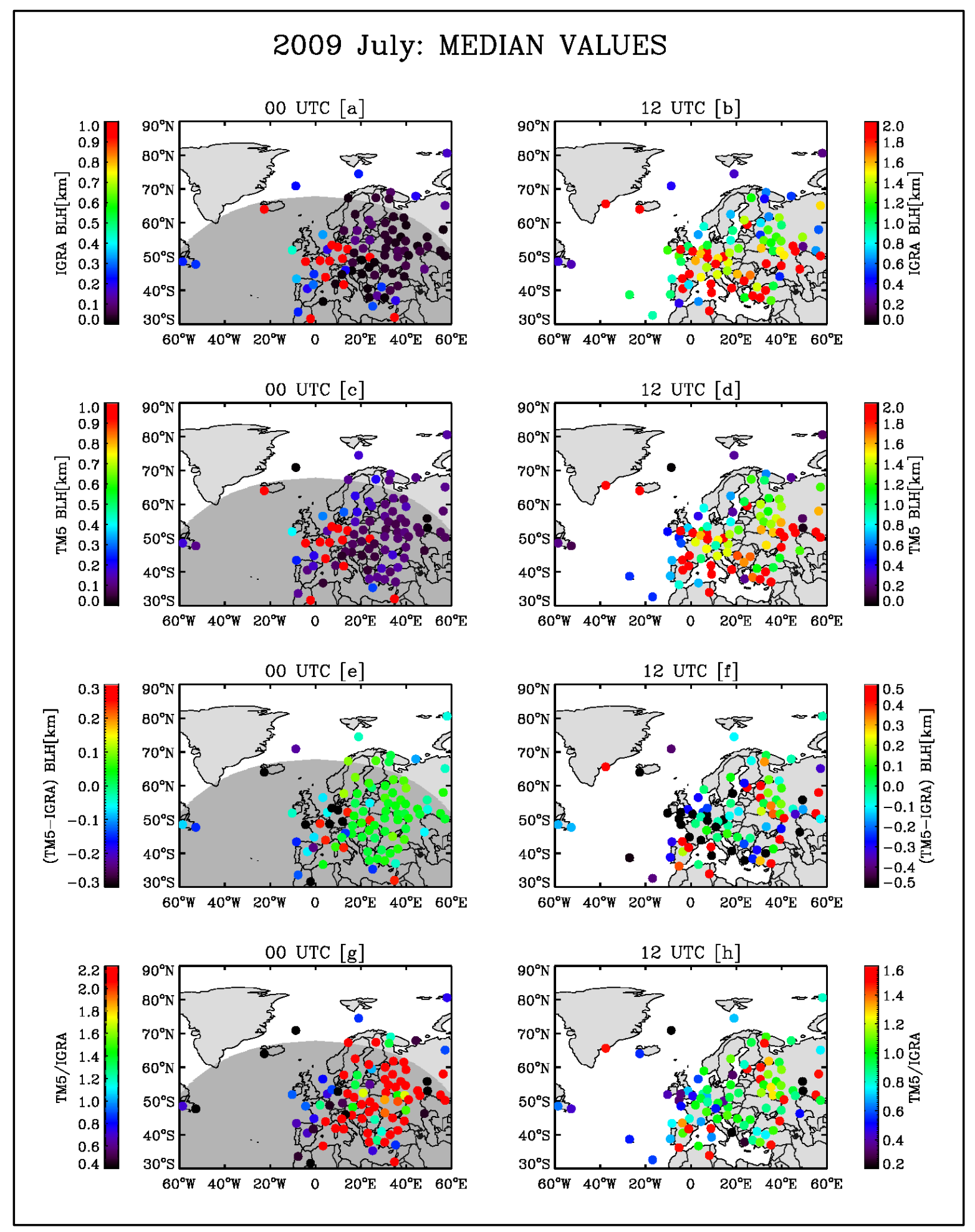

Figure S13: As for Figure S12, but for July 2009 


\section{Time series of ${ }^{222} \mathrm{Rn}$ activity concentrations}

We simulate ${ }^{222} \mathrm{Rn}$ concentrations using either the InGOS ${ }^{222} \mathrm{Rn}$ flux map, or constant ${ }^{222} \mathrm{Rn}$ fluxes (see Section 3.3). Furthermore, we apply four different convection schemes in the TM5 model (for the InGOS ${ }^{222} \mathrm{Rn}$ flux map based simulations only). These different simulations are labelled by the following acronyms:

- FC_CT: constant ${ }^{222} \mathrm{Rn}$ fluxes, and default convection scheme in TM5 based on Tiedtke [1989]

- FI CT: InGOS ${ }^{222} \mathrm{Rn}$ flux map, and default convection

- FI_CS: InGOS ${ }^{222}$ Rn flux map and revised slopes scheme (see Section 3.1 of the text)

- FI_CE: InGOS ${ }^{222}$ Rn flux map and the updated convection scheme based on ECMWF reanalyses (see Section 3.1 of the text)

- FI_CU: InGOS ${ }^{222} \mathrm{Rn}$ flux map, updated treatment of slopes and updated convection scheme based on ECMWF

For other details see Section 3.4 of the text

We show in the following the time series for year 2009 


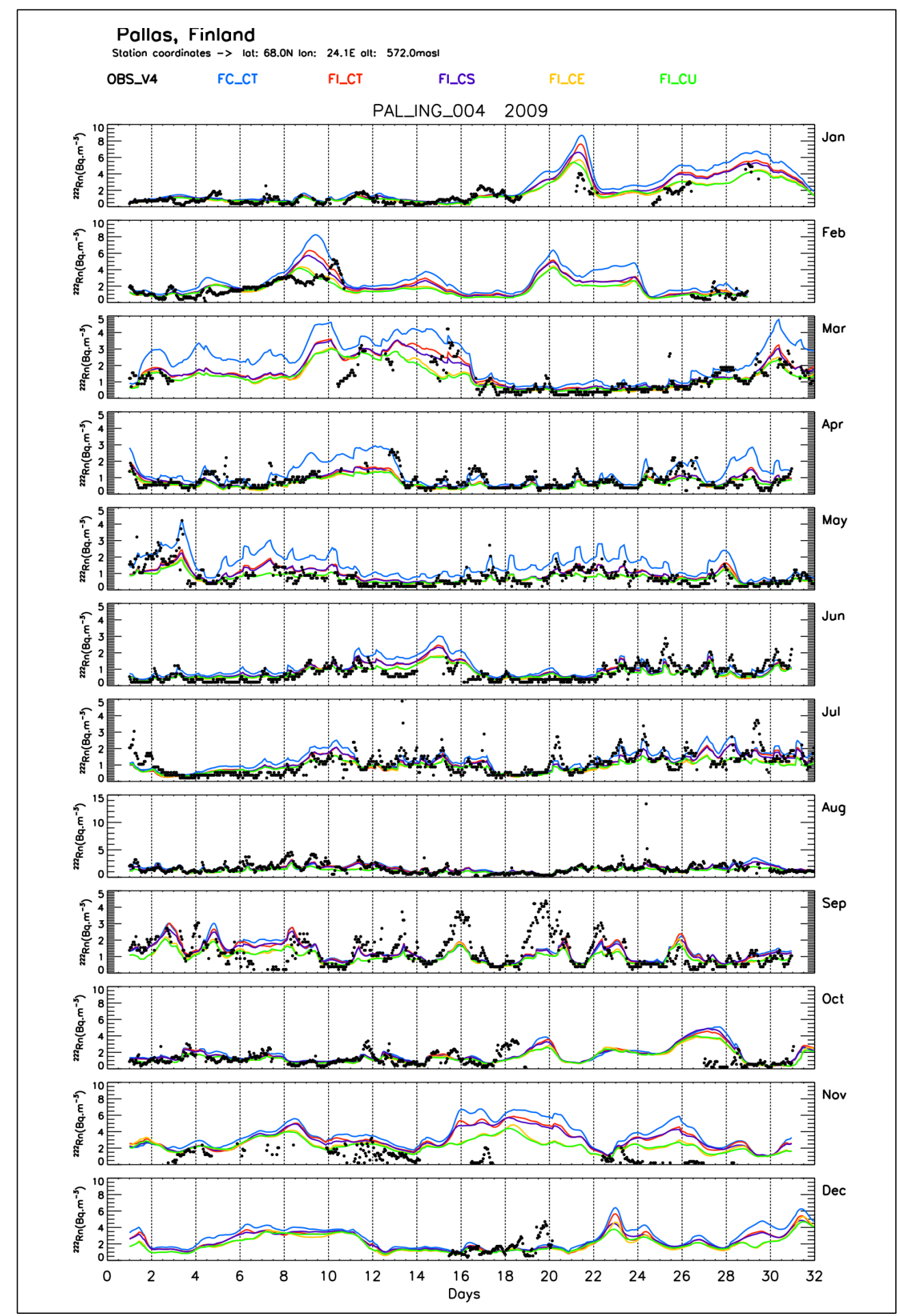

Figure S14: The time series of the observed and simulated radon activity concentrations at Palas [PAL] for 2009. The observed radon concentrations are shown by the dots $(\bullet)$. The model simulations are obtained from constant emissions (solid blue line; FC_CT) and four from INGOS emissions (solid red line: FI_CT, solid violet line: FI_CS, solid orange line: FI_CE, and solid green line: FI_CU). The different acronyms are defined in the previous page. 


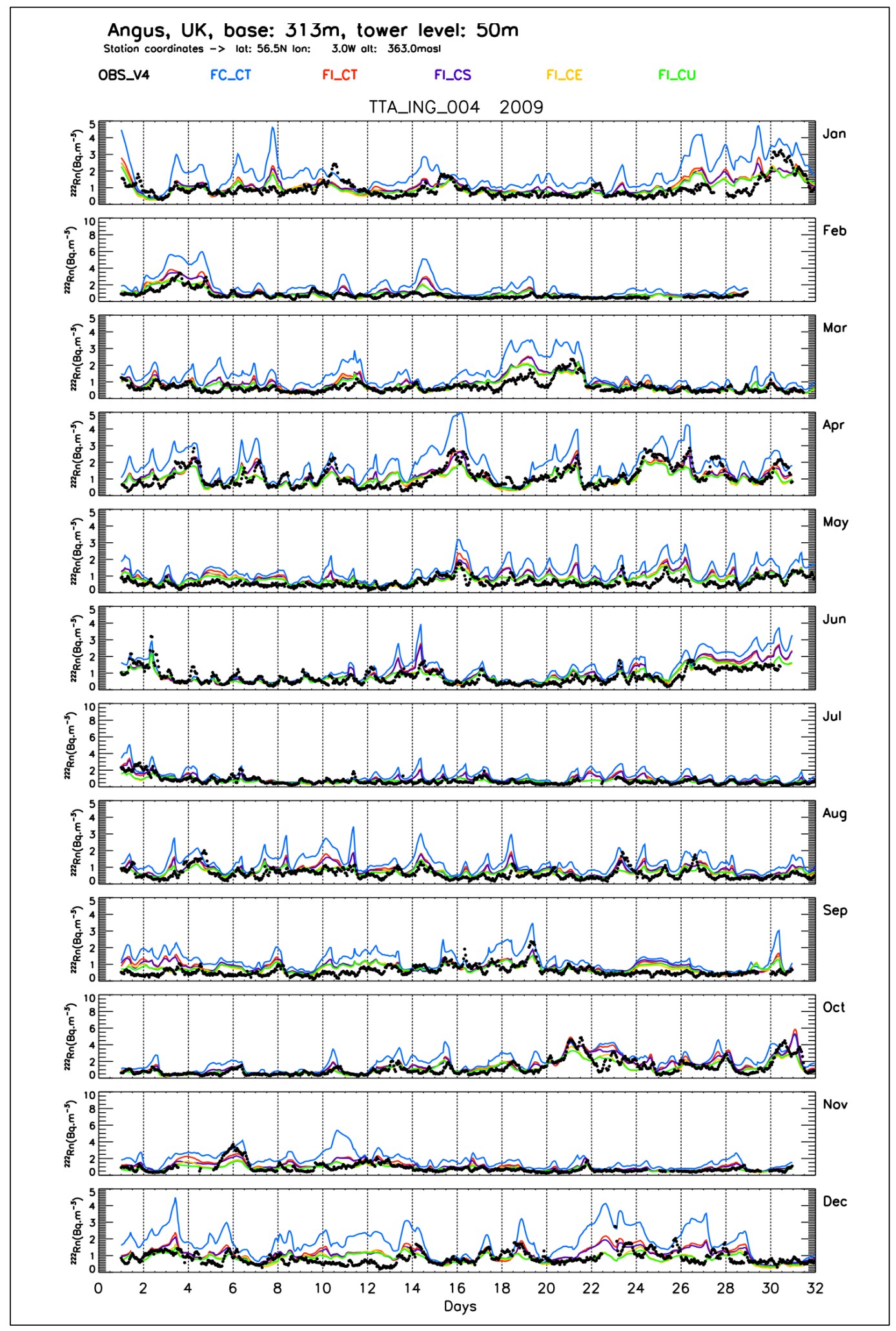

Figure S15: As Figure S14, but at Angus (TTA) 


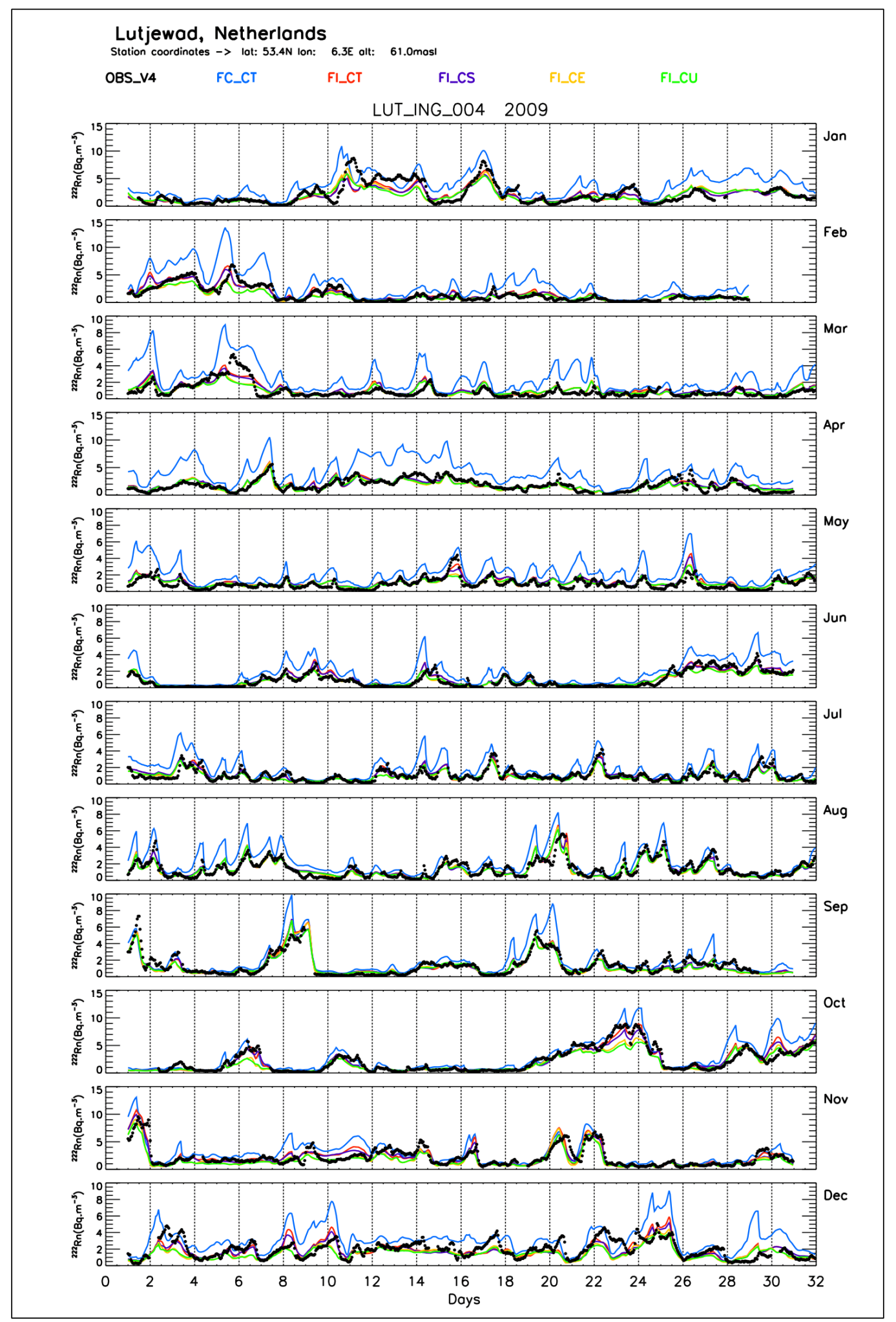

Figure S16: As Figure S14, but at Lutjewad (LUT) 


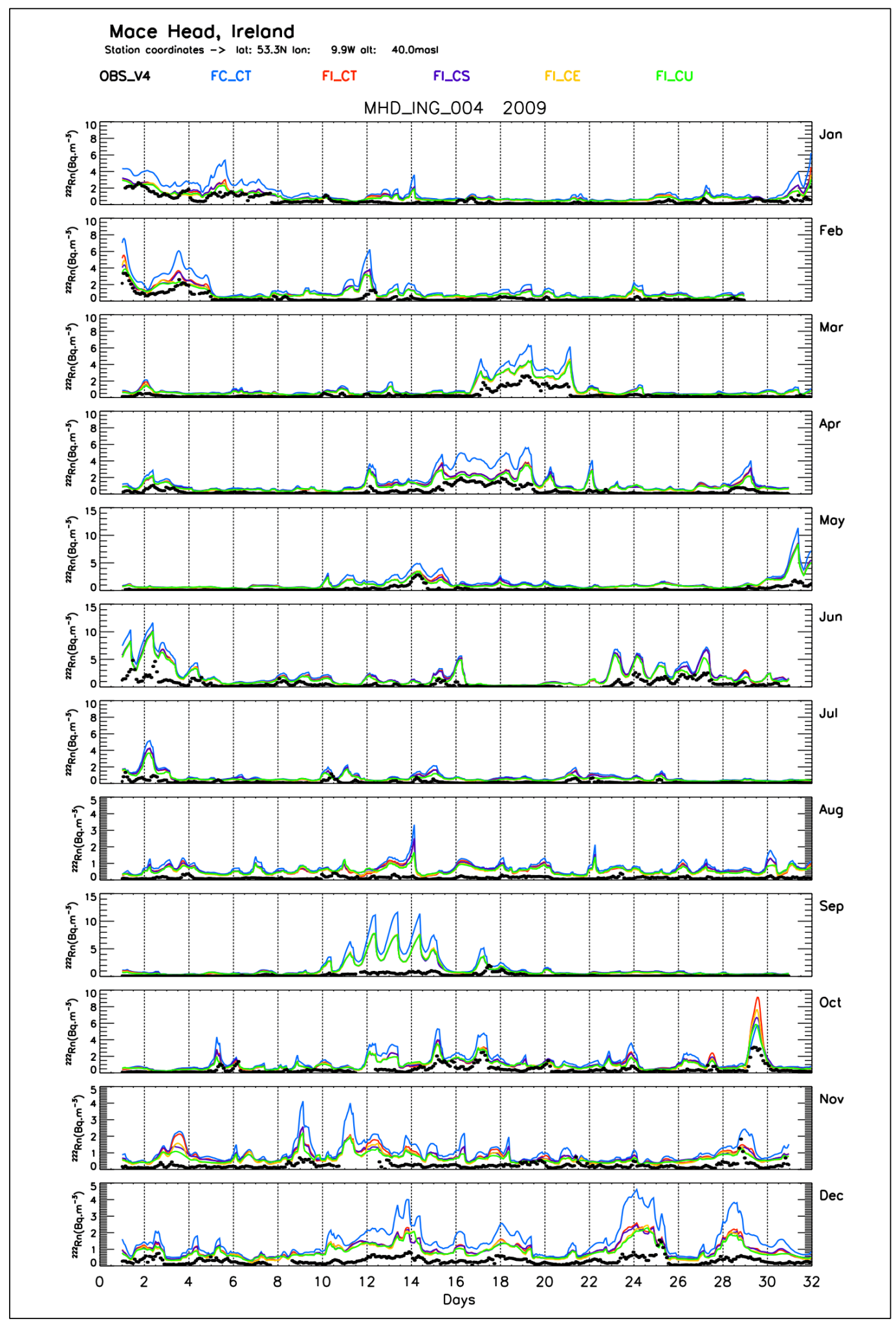

Figure S17: As Figure S14, but at Mace Head (MHD) 


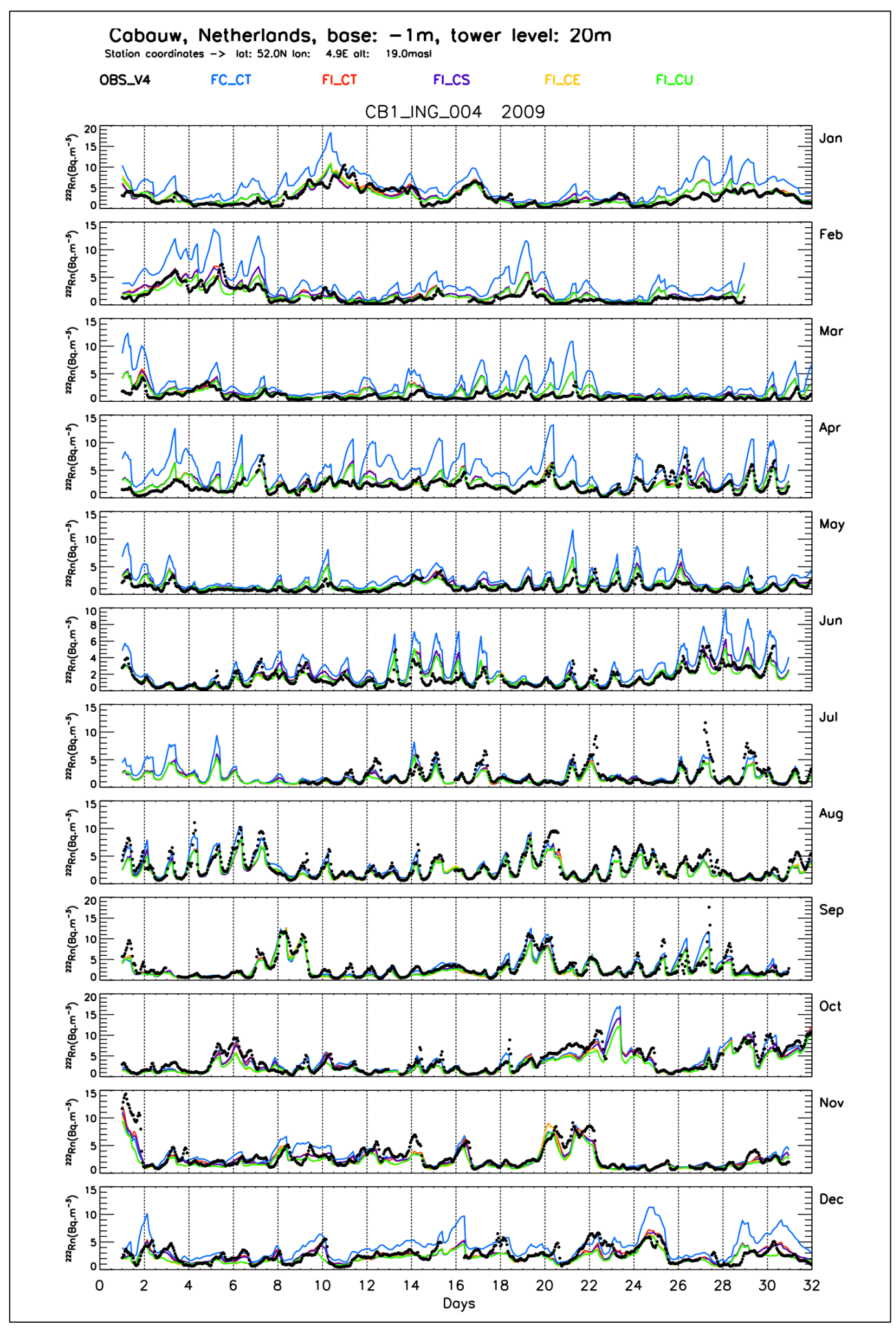

Figure S18: As Figure S14, but for Cabauw at $20 \mathrm{~m}$ [CB1] 


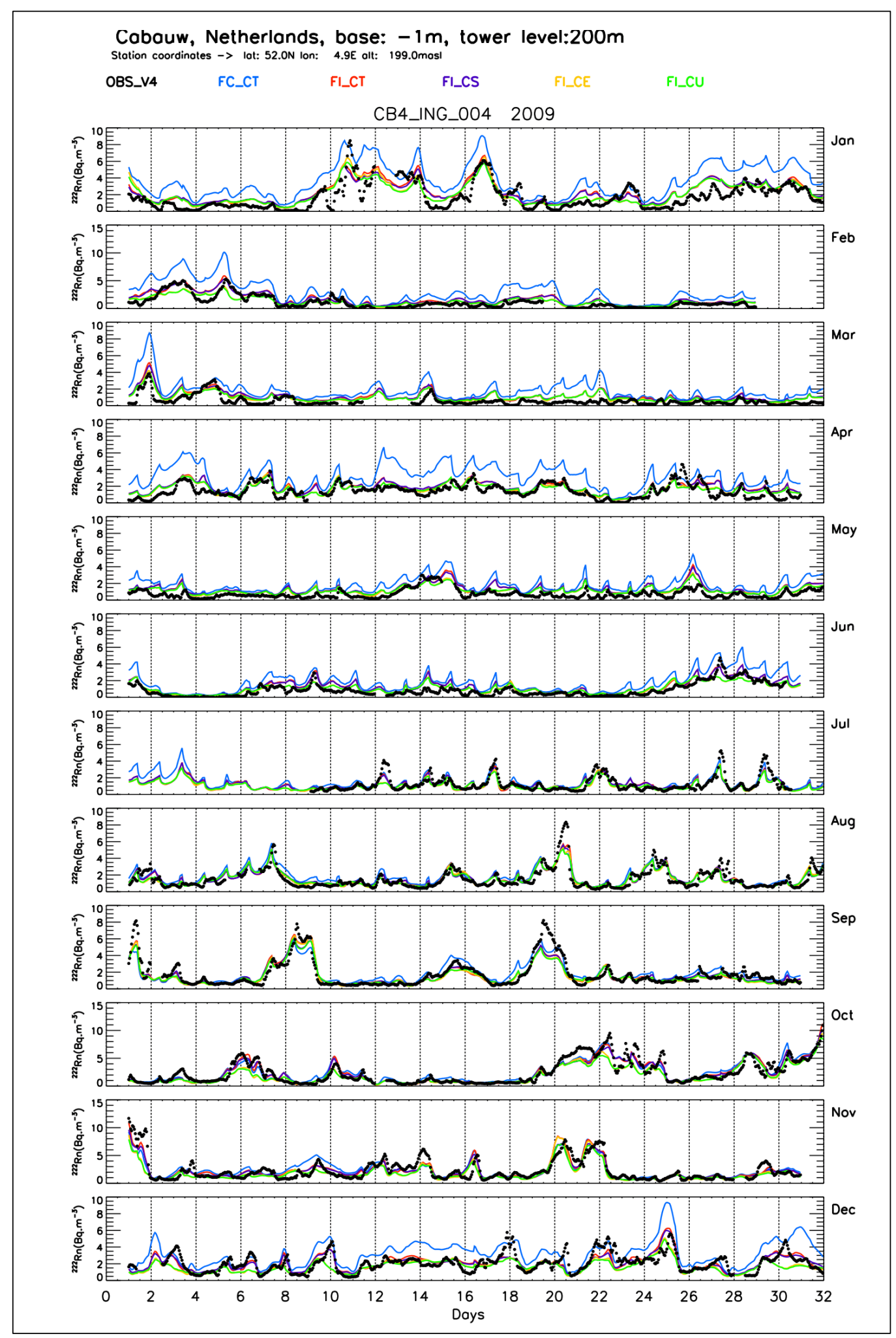

Figure S19: As Figure S14, but for Cabauw at $200 \mathrm{~m}$ height [CB4] 


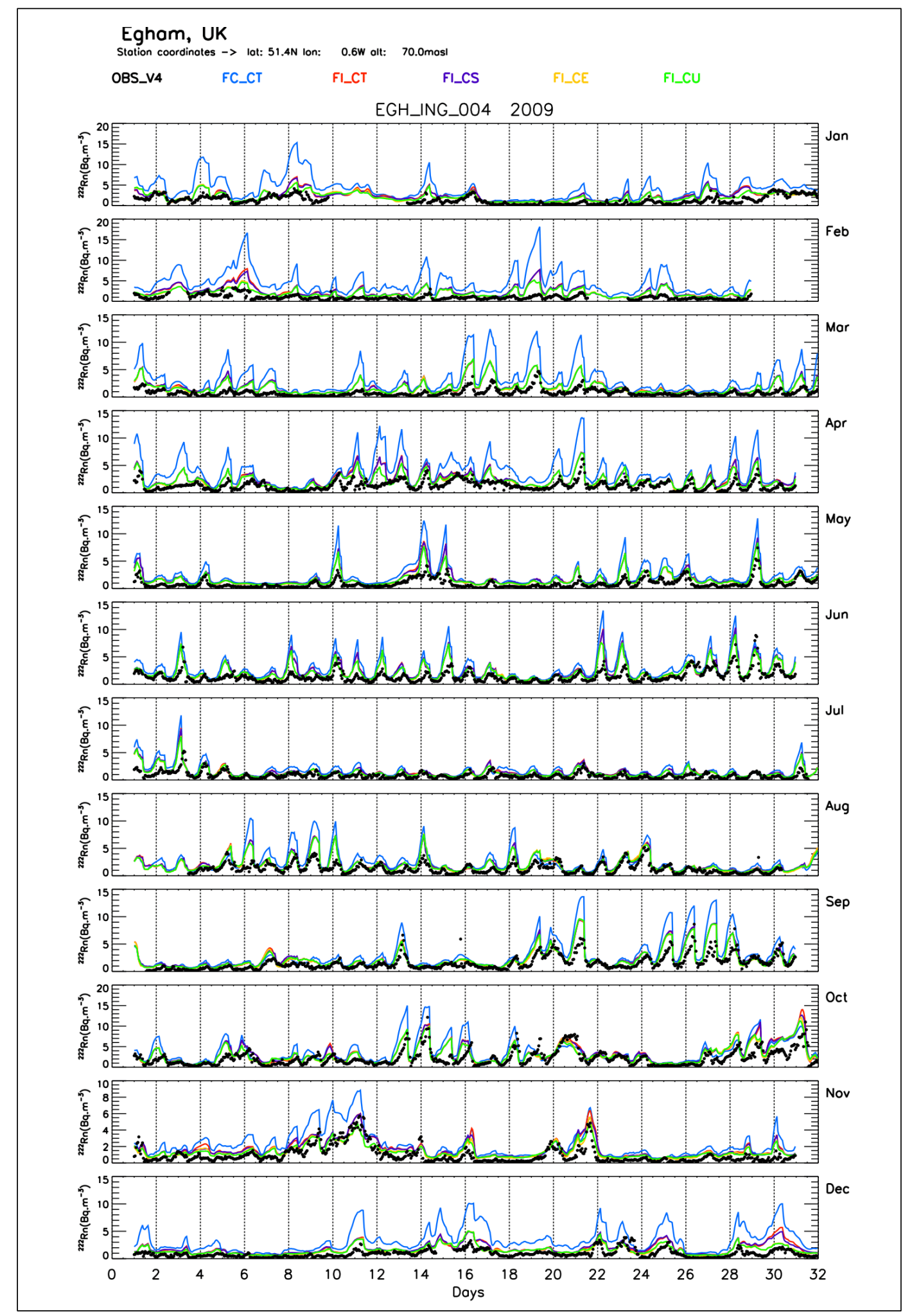

Figure S20: As Figure S14, but at Egham (EGH) 


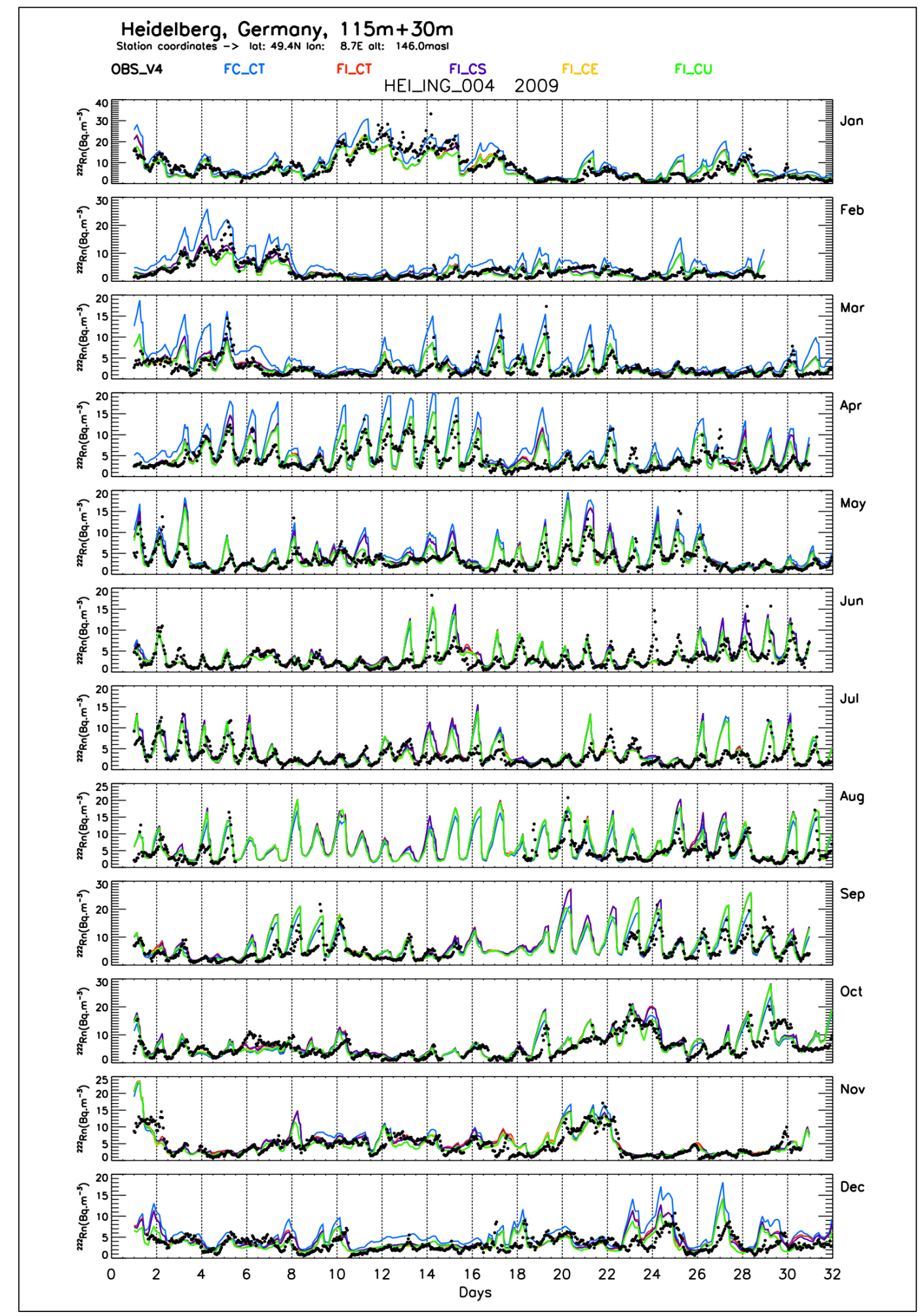

Figure S21: As Figure S14, but at Heidelberg (HEI) 


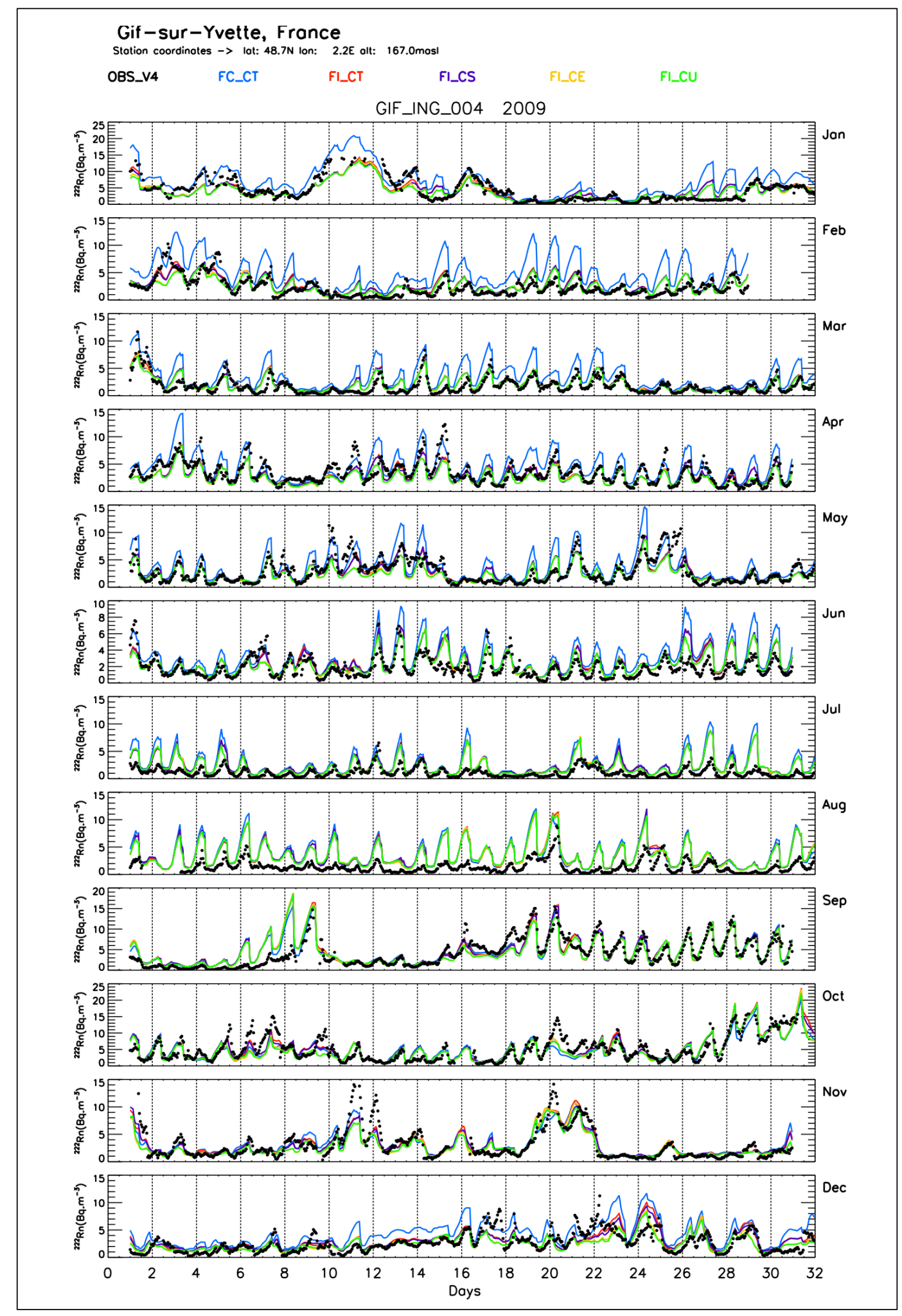

Figure S22: As Figure S14, but at Gif sur Yvette (GIF) 


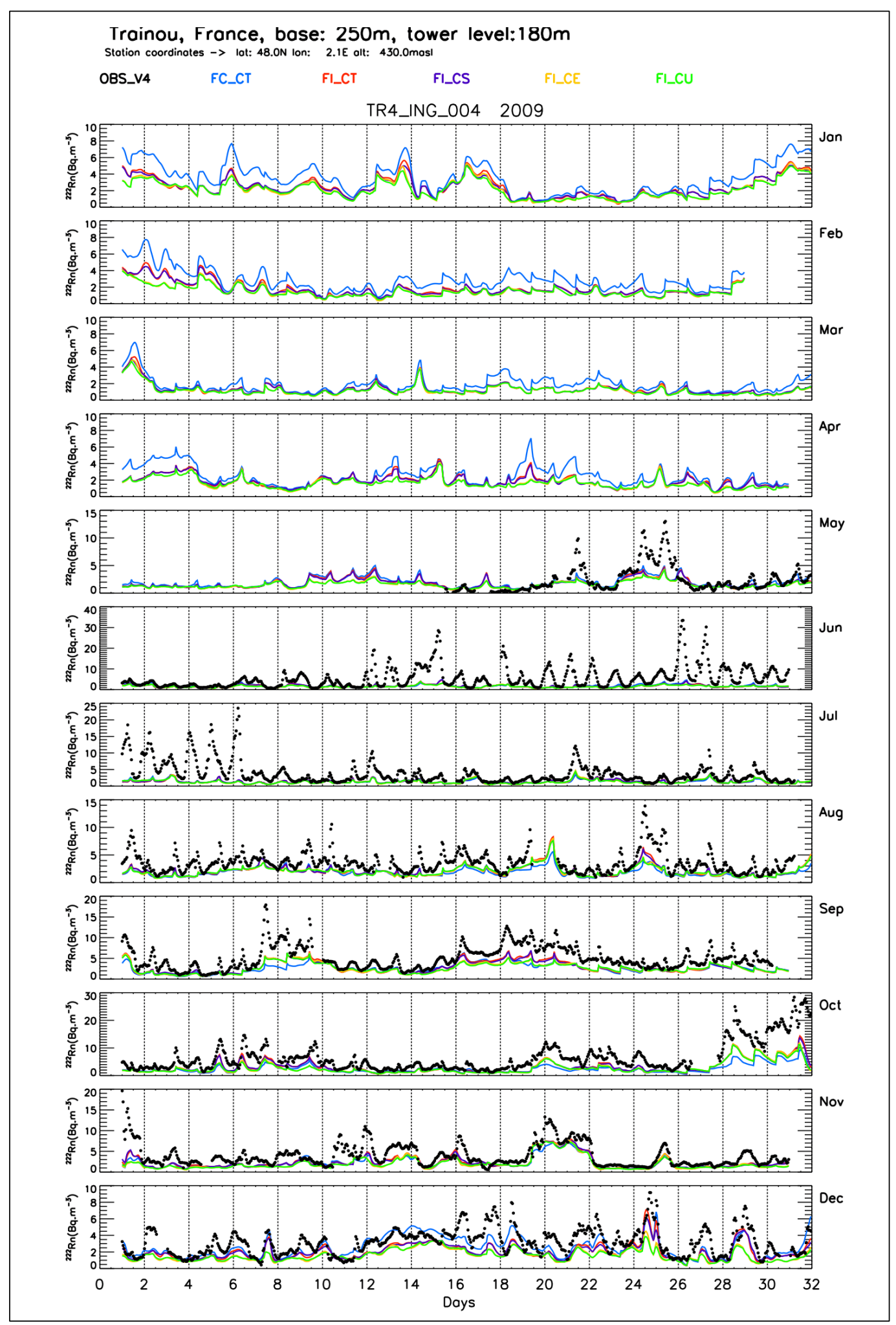

Figure S23: As Figure S14, but for Trainou at $180 \mathrm{~m}$ [TR4] 


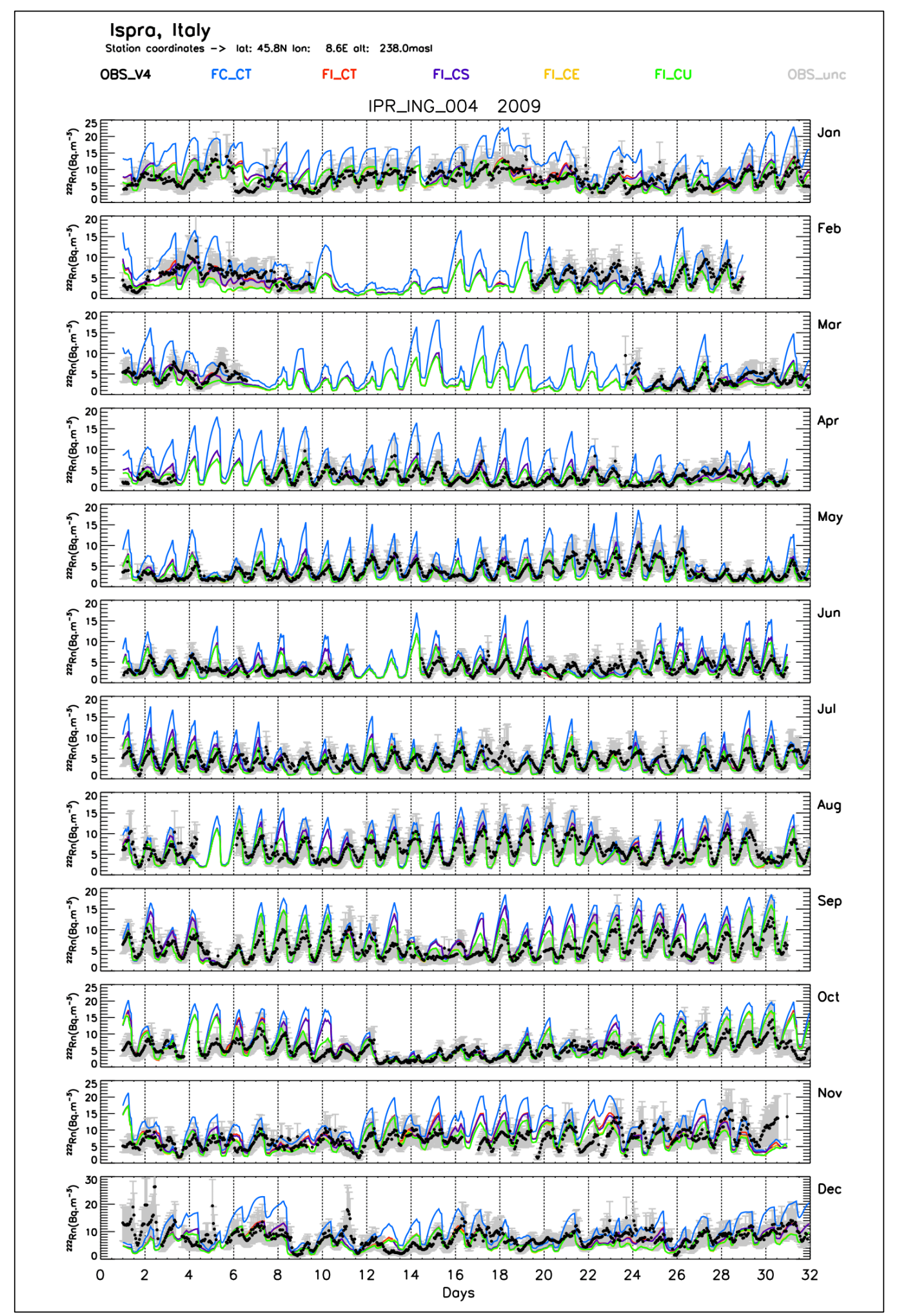

Figure S24: As Figure S14, but at Ispra (IPR). This figure includes also the uncertainties in the ${ }^{222} \mathrm{Rn}$ activity concentrations (grey shaded area) from the wind-speed dependent correction of the measurements ('normalization' to $15 \mathrm{~m}$ inlet height; see section 2.2). 